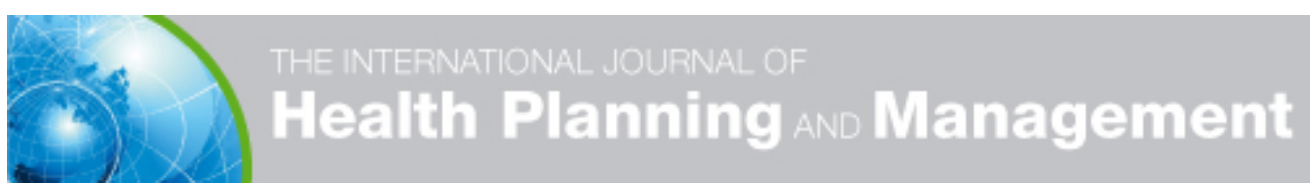

\title{
Calling for confirmation, reassurance and direction: investigating patient compliance after accessing a telephone triage advice service
}

\begin{tabular}{|c|c|}
\hline Journal: & International Journal of Health Planning and Management \\
\hline Manuscript ID & HPM-19-00254.R1 \\
\hline Wiley - Manuscript type: & Research Article \\
\hline $\begin{array}{l}\text { Date Submitted by the } \\
\text { Author: }\end{array}$ & 24-Aug-2019 \\
\hline Complete List of Authors: & $\begin{array}{l}\text { Siddiqui, Nazlee; University of Tasmania Faculty of Business, Australian } \\
\text { Institute of Health Services Management } \\
\text { Greenfield, David; University of Tasmania Faculty of Business, Australian } \\
\text { Institute of Health Service Management } \\
\text { Lawler, Anthony; Department of health Tasmania; University of } \\
\text { Tasmania }\end{array}$ \\
\hline Keywords: & $\begin{array}{l}\text { telephone triage advice service, emergency department, appropriate } \\
\text { care, care integration }\end{array}$ \\
\hline
\end{tabular}

\section{SCHOLARONE" Manuscripts}


Calling for confirmation, reassurance and direction: investigating patient compliance after accessing a telephone triage advice service

Short running title: Calling for confirmation, assurance and direction

Authors:

Nazlee Siddiqui, PhD*

Lecturer, Australian Institute of Health Service Management, University of Tasmania

David Greenfield, PhD

Professor and Director, Australian Institute of Health Service Management, University of Tasmania

Anthony Lawler, MBBS, FACEM

University of Tasmania

Department of Health Tasmania

* Corresponding author

Contact details of corresponding author:

Business: ++ 61286720000

Email: Nazlee.sidiqui@utas.edu.au

Acknowledgement: We thank the Telephone triage advice service (TTAS) organisation and David Dean, from Chappell Dean, for their assistance with the study.

Funding: We acknowledge funding from Chappell Dean to conduct the study.

Conflict of interest statement: Authors declare that they have no conflict of interest.

Manuscript data:

Words in abstract: 199

Words in body: 3255

Tables: 5

Figures: 0

References: 49 


\begin{abstract}
Understanding the influence of a telephone triage advice service (TTAS) on patients seeking care is critical to realise enhancements in patient care, functioning of emergency departments (EDs), and effectiveness of the health system. This study addresses the question: what influence does a TTAS have on a patient's attendance at an ED and the wider health system?

Records from 2016-2017 of 12,741 calls from a national TTAS were linked to 72,577 ED presentations to a hospital in regional Australia, retrospectively. Matching criteria included patient within the hospital's statistical local area code, age, gender, and ED attendance within eight hours of TTAS call. Five statistical analyses of the data were conducted.
\end{abstract}

There were 2,857 matches. TTAS patients accessing the ED had a slightly higher proportion of women and a greater proportion of children under four years than usual. When TTAS confirmed callers' inclination for ED care, however only up to $69 \%$ subsequently attended the ED. When TTAS redirected others initially less inclined to more urgent care, up to $62 \%$ attended the ED.

TTAS empowers vulnerable patients to access appropriate and timely services and promotes clinical and functional integration of care. Improvements of TTAS can come through investigation of callers' compliance factors.

Keywords: telephone triage advice service, emergency department, appropriate care, health system, empirical study, care integration 


\section{Introduction}

What influence does the use of a telephone triage advice service (TTAS) have on a patient's ED attendance and the health system? This simple question encapsulates a complex issue. An anxious patient in their own home, with a perceived pressing and urgent medical problem (at least from their perspective) is, following discussion but not physical examination, given professional advice. Subsequently the patients take decisions and actions that impacts on their own health, an ED and health system care outcomes. $^{1,2}$ Understanding and responding effectively to this issue is critical to realising enhancements in the quality of care and outcomes for individuals, patient cohorts, ${ }^{3-6}$ the functioning of EDs and the hospitals that encompass them, and the health system more broadly. $3,7,8$

Taking a broad view of TTASs' influence, from a health system perspective, is fundamental. ${ }^{9}$ Patients attending services inappropriate to their need results in poorer health outcomes, through inefficiencies, overcrowding, frustrations and complaints from staffs, patients and families. ${ }^{10-15}$ This is particularly critical for Eds, as they serve as the primary gateway to the acute healthcare system. The effective functioning of the ED system is a focus of practice and policy reform for many countries, with a range of strategies implemented.12,15,16 Strategies internal to the ED include designated holding areas, fast-tracking of patients, accelerated triage and registration, and escalation policies. ${ }^{10,12,13,15}$ Strategies external to the ED include, various methods of hospital diversion and demand management, such as TTAS, stand-alone GP services; and GP Super Clinics. ${ }^{17}$ The TTAS, providing advice to patients prior to accessing EDs or other primary care services, uses the avenue of external strategies to directly influence the functioning of ED and the health system more broadly. ${ }^{18,19}$

Research into patient attendance at an ED, following usage of a TTAS, is difficult to compare. As an example, a 2010 Canadian study records a compliance rate with TTAS decision for ED assistance within 24 hours, at 53\% 20; whereas a 2002 study from the United States reported a compliance rate within 48 hours, at $79 \% .^{21}$ Comparing the impact and outcomes is fraught, as many studies are: dated; sparse; variable for time periods; reflect different health systems; focus on differing service availability (during work hours or after-hours); and, differ in triage models (nursing vs 
medical staff). Various studies on the topic have been conducted across a range of health systems and time periods though, including the United Kingdom, ${ }^{22-24}$ Canada, ${ }^{20}$ Switzerland, ${ }^{25}$ the United States, ${ }^{26,27}$ the Netherlands, ${ }^{22,28}$ Pakistan, ${ }^{29}$ Denmark, ${ }^{22}$ and Australia. 9,30,31

Questioning the effectiveness of a TTAS illuminates a 'wicked problem' in healthcare, ${ }^{32}$ that of a complex challenge embedded within a multilayered context, involving a diverse range of stakeholders with divergent thinking on the issue. Unsurprisingly, a recent systematic review identified that TTAS involves the dynamics of at least nine key indicators-access, appropriateness, compliance, patient satisfaction, cost, safety, health service utilisation, clinician workload, and clinical outcome. ${ }^{18}$ TTAS stakeholders are telephone triage, primary care and ED clinicians, patients and their families, policy makers, and the community. Actions, interventions or changes, temporary at best until the context evolves anew, are impacted through cooperation, systems analysis and multiple strategies. ${ }^{32}$

The key task, from all stakeholder perspectives, is a timely patient assessment and positive care outcome that manages clinical safety and risk appropriately. In the virtual telephonic environment, the task is complicated by the inability to see or touch the patient with decision-making relying on assessment algorithms, normally computer assisted. ${ }^{33,34}$ In practice, the assessment is mediated by the professional's ability to elicit information from and manage the emotions of the caller, and knowledge of when to follow, or deviate from, the assessment algorithms. ${ }^{35-37}$

Even so, TTAS have been assessed as providing safe, effective triage decisions and are positively regarded by users and providers. TTAS referrals were found appropriate with low triage acuity outcomes recorded, ${ }^{2,9,38}$ and the consultations receive positive reports for patient satisfaction, ${ }^{2,18,39}$ management of workload of general practitioners, ${ }^{18}$ and patient-doctor satisfaction. ${ }^{38,39}$ An outright decision on the appropriateness of TTAS decisions is, however difficult. The challenge is that the definition for 'appropriateness' varies considerably and the reported rate for TTAS disposition appropriateness ranges, between $44 \%-98 \%{ }^{18,37,40}$ 
Within the diversity of studies, across a range of settings, a key issue requiring greater understanding is the influence of TTAS on patients' care-seeking behaviour and subsequent impact on the health system. ${ }^{18}$ TTASs' influence on patients' care-seeking behaviour positively impacts the health system; only when TTAS recommends appropriate care. That is, the care is resource efficient and suitably urgent and callers follow the advice recommended. ${ }^{37,40}$ In the context of an individual TTAS caller, determining the outcome involves tracking movement of care sought, recommended and accessed. The driving force of this movement is the exchange between the caller and the triage health professional that aligns the caller's need and action to the TTAS recommendation. ${ }^{9}$ The exchange can alter the patient's care-seeking behaviour from the caller's initial inclination. ${ }^{37}$

Understanding the outcomes and broader implications of the above issues is important for improved functioning of the health system and deserves greater attention. ${ }^{9}$ This study aims to address these issues through answering the question: what influence does a TTAS have on patients' attendance of the ED and the health system?

\section{Methods}

\subsection{Data linkage}

This is a data linkage study, retrospectively examining records from the two-year period of January 2016 to December 2017. An Australian national TTAS' records $(n=12,741)$ were linked to ED presentations $(n=72,577)$ in a regional hospital. Matching criteria included: patient from within the hospital's statistical local area code; age; gender; and ED attendance within eight hours of TTAS call. A record was rejected from the linking task, whenever there was possibility of having multiple matches with ED attendances. There were 2,857 unique matches. Approval for ethics protocol of the study was received from the administering university's human research ethics committee (protocol number: H0016886).

\subsection{Study measures and analysis}

Five analyses of the data set were undertaken. In some analysis, a record was excluded if the specific data item was missing. Hence, there is slight variability in the numbers across the work undertaken. 
First, a profile analysis was completed. Factors examined, using percentage breakdown, included age, gender, and international classification of diseases (ICD)10 categories (Table 1 ).

Second, we analysed, via Chi-square analysis at 95\% confidence interval, TTAS's influence on patients' care-seeking intention, assessed medical need and ED attendance (Table 2). This analysis tracked movement based on the patient's initial inclination and then recording TTAS's recommendation. The process of TTAS's recommendation involved computerised algorithm and decision-making by nurse and/or general practitioner as previously reported. ${ }^{9}$ In this study, the reporting of TTAS's recommendation was categorised into high urgency care, which consists of emergency care via 'calling ambulance' and 'self-transport attendance' (Table 2, Column 2 and 3). From this data, the patient's compliance, within eight hours, with TTAS' recommendation for ED attendance was calculated.

Third, the number of ED presentations per patient was examined. This was performed using Chi-square analysis at 95\% confidence interval (Table 3 ).

Fourth, an investigation of callers' ED triage outcomes was completed, again using Chi-square at $95 \%$ confidence interval (Table 4). Triage outcome data categorised according to the Australasian Triage Scale, was accessed from the hospital. Scores ranged from immediate medical attention (category 1), medical attention within 10 minutes (category 2), medical attention within 30 minutes (category 3), medical attention within one hour (category 4), and medical attention within two hours (category 5).

The fifth and final analysis involved the assessment of appropriate ED care for the TTAS caller and non-TTAS caller cohorts (Table 5). Investigating ED appropriate care for these cohorts enabled a comparative view of TTAS's influence towards clinically safe and efficient care. Consistent with previous reporting of ED appropriate care ${ }^{41}$ and recognising the high prevalence of readmission in Australia, ${ }^{42}$ attendance was assessed as appropriate when patients were: triaged into categories 1, 2 or 3 , admitted to hospital, or had been admitted recently. 


\section{$3 \quad$ Results}

There were 2,857 unique matches, drawn from linking ED presentations with TTAS callers. These cases represent 1164 (41\%) male and 1693 (59\%) female patients. The patient cohort showed a spread across all age and disease groups (Table 1). The three age categories reflecting at least $20 \%$ of the cohort are children aged up to 4 years, adults in age range of 20-39 years, and adults in age range of 40-59 years.

\section{Insert Table 1 here}

The initial care inclination of TTAS callers, the advised recommendation for ED attendance by TTAS (either via ambulance or self-transport), and caller's subsequent action of (non-) compliance with TTAS's recommendation were assessed (Table 2). The assessment covered 10,819 of 12,741 callers, as the remainder had multiple possible matches with ED presentations that could not be separated.

\section{Insert Table 2 here}

The initial inclination of TTAS callers was divided across three care options - attend the ED via ambulance or self-transport (Table 2, Column 1, Rows 1 and 3), receive advice from the TTAS (Table 2, Column 1, Row 2), or obtain primary care either via the GP or homebased care (Table 2, Column 1, Rows 4 and 5).

Across the different types of initial inclination sub-cohorts, TTAS recommended high urgency care $18-100 \%$ of the time (Table 2, Column 2). The TTAS confirmed callers who perceived they required high urgency care - who sought ED care via ambulance and self-transport, $100 \%$ and $36 \%$ respectively. TTAS also directed callers to high urgency care when they were not initially inclined or were unsure to do so. Twentynine percent of callers who were initially inclined to just seek advice from TTAS, $18 \%$ who were initially inclined to see GP, and $25 \%$ who were initially inclined to seek homebased care were recommended to attend high urgency care. However, as TTAS recommendations for all of the three care options are combined, it was seen that 
majority of the callers were directed to low urgency care such as attending GP or homebased care. TTAS' recommendation for ED care via ambulance, for all subcohorts, was lower than self-transport to ED care (Table 2, Column 3).

Patient compliance outcomes with TTAS recommended ED attendance by ambulance or self-transport, across initial inclination categories, ranges from 29-69\% (Table 2, Column 4). Higher compliance for ambulance service usage to attend ED was recorded, for all sub-cohorts of initial inclinations, with a range of 53-69\%. Conversely, ED attendance compliance through self-transport was lower, for all sub-cohorts of initial inclinations, with a range of $29-53 \%$. The lowest compliance rate - $29 \%$, corresponds to when TTAS recommended ED via self-transport to the sub-cohort initially inclined for ambulance care.

High frequency visitors to the ED - those with 20 or more presentations - were identified as having a relatively higher share of TTAS-linked ED access than those with fewer presentations (Table 3, Column 4, Rows 1 and 2). However, the high frequency ED visitors' sub-cohort were less numerous than other sub-cohorts. At a practical level, high frequency visitors' ED usage is also equivalent to the middle (Table 3, Column 4, Rows 3 and 4) or bottom (Table 3, Column 4, Rows 5 and 6) subcohorts.

\section{Insert Table 3 here}

Presentations by patients who attend the ED after utilising the TTAS, corresponds to $4 \%$ of all presentations for year 2016-17. They are also proportionally more highly represented among category 3 triage allocations (Table 4, Column 4).

\section{Insert Table 4 here}

Appropriate presentations to the ED, were categorised according to the assessment outcome and whether the patient had utilised the TTAS service (Table 5). Examination of the two cohorts - non-TTAS callers and TTAS callers - shows comparable figures for all assessment outcomes. For both cohorts, the majority of the appropriate ED 
presentations were triaged by the hospital ED as category 1, 2 or 3 . However, the subcohort of TTAS callers is expected to be less standardised, than for the non-TTAS callers, given the higher range of confidence interval (Table 5, Column 3).

\section{Insert Table 5 here}

\section{Discussion}

This study investigated what influence a TTAS has on a caller's ED attendance and the health system, through analysing presentations to a regional tertiary hospital. This is a wicked problem impacting on individuals, patient cohorts, the ED and the health systems, the community and professionals within it. ${ }^{18}$

\section{Study cohort comparison to previous studies}

The TTAS patient cohort attending the ED is reflective of previous studies, showing representation across sex, ${ }^{9,38}$ age, 9,38 and disease categories. ${ }^{38,43}$ However, the cohort's ED presentation rate of $4 \%$ was higher than previously reported. ${ }^{17}$

\section{Study cohort comparison to the State ED attendance}

There is congruence between the TTAS and State's general ED cohort across the two major disease categories for which patients accessed services, namely injury/poisoning and symptoms involving respiratory/digestive systems. The TTAS cohort attending the ED differs in two aspects to the patient cohort attending the ED in the State. First, children up to age 4 contributed $8.8 \%$ of all emergency presentations in the State, in comparison to $22 \%$ of ED presentation via the TTAS. Second, the ED female patient cohort for the State is lower than those who accessed the TTAS, the figures being $50 \%$ and $59 \%$, respectively. ${ }^{44}$

The distinctiveness of the TTAS cohort, with high representation of very young children, infants and women, demonstrates that the TTAS provides an important service for particularly vulnerable members of the community. The TTAS allows families and patients from across vulnerable populations to review their concerns with 
a health professional prior to accessing services, receive immediate emotional and psychological support, and obtain medical advice for action. This finding supports recent studies that identified this important role of telephone triage, evidencing TTAS being more effective when the caller's degree of worry is considered. ${ }^{45}$ Being able to respond to caller's emotions and knowing when to follow or depart from the assessment process to determine the appropriate recommendation is critical for an effective service. ${ }^{35-37}$

A relevant implication of this is the potential for improved patient care, ED efficiencies and appropriate use of health services, through greater understanding of, and appropriate management of, the TTAS patient cohort. Also, considering the caller subcohort of those who attend the ED frequently reinforces the value of such work. Though they are few in number, these patients consume significant resources in the ED. Applying a patient-centred approach in delivering TTAS, as has been proposed in emergency care ${ }^{46}$ is one opportunity to realise further improvements.

\section{Care outcomes from the TTAS}

The TTAS both confirmed those who were inclined to seek ED care, as well as redirecting others initially less inclined, to more urgent care in a timely way. This outcome reflects similar studies from a range of contexts, ${ }^{17}$ wherein callers used the TTAS to confirm their initial inclination and need for help. ${ }^{38}$

The transition from TTAS caller to ED patient, however, is not a guaranteed step. For the sub-cohort initially inclined to call an ambulance, where the TTAS confirms this need, only a fraction became patients in the ED. Significant numbers of patients did not access services when advised to do so. This may represent a clinical risk where callers ignore both their own inclination and expert guidance to attend for urgent review. The TTAS did not substantially influence a significant number of callers' behaviour in these cases. To improve service efficiency, of both TTAS and EDs, further research exploring reasoning and events that determined these outcomes is warranted.

In those sub-cohorts, where less urgent care was the initial inclination, but the TTAS recommendation was for higher urgency care, the conversion from caller to patient 
was also limited. A substantial proportion of these sub-cohorts did follow advice to transition from TTAS caller to ED patient. The TTAS effectively influenced callers' health-seeking behaviour in these cases, ${ }^{37}$ and failed to do so for other patients, who followed their own initial inclination.

Moreover, a substantial portion of the callers who were inclined for high urgency care, received advice to access low urgency care, such as attending GP or home-based care. In doing so, the TTAS also encouraged appropriate resource utilisation across the health system, in the ED, GP and home-based care..$^{3,7,8}$

The reported levels of compliance with TTAS's recommendation to attend ED, varied from the earlier published range; that is, $29-69 \%$ compared to $52-68 \%$.9,43,48 Variation in compliance rates is a known issue. ${ }^{40}$ Behaviour outcomes are shaped by a range of factors, including caller cohorts' residential location, ${ }^{49}$ age range, ${ }^{40}$ and disease category. ${ }^{43}$ Additionally, study inclusion criteria influence results. For example, our study measured compliance rate within eight hours of ED attendance from TTAS's recommendation, in contrast to 24 hours in the case of another study. ${ }^{9}$ Notably, the compliance rate dropped to the lowest point when TTAS redirected callers to access ED care via self-transport rather than ambulance. This finding reveals a new factor shaping callers' compliance with TTAS's recommendation and can be investigated further in future studies.

\section{Opportunity to promote integration of care and health system effectiveness}

TTAS promotes better integration of care, advising patients at the intersection of functional and clinical dimensions service provision. ${ }^{47}$ TTAS facilitates the functional dimension of care integration, offering trustworthy information on the provisional diagnosis of a patient's condition and their need to access services. Simultaneously, TTAS performs clinical integration by being able to predict appropriate triage categories with an accuracy that is comparable to regular (non-TTAS) ED services. ${ }^{2,9,38}$

There is further opportunity to enhance the positive contribution of TTAS to the integration of care and health system effectiveness. TTAS directing callers towards 
appropriate care has system-wide improvement implications, including enhanced quality and care outcomes for patients, ${ }^{35}$ improved patient experiences, particularly for those identifying as highly anxious, ${ }^{9}$ and the provision of appropriate pathways for callers to GP and other primary care services. ${ }^{19}$

In urgent cases, being able to appropriately transition callers to attend the ED in a timely fashion is critical. By contrast, identifying and preventing callers with less urgent conditions from attending the ED, and directing them to appropriate care for their needs, serves both the consumer and the clinician. This reinforces the importance of understanding the TTAS caller profile, as compliance with TTAS recommendations is highly sensitive to callers' context, including age, income, disease type and location of residence. $9,43,49$

\section{Study strengths and limitations}

Data matching is a complex process and open to possible errors, given the patient variables involved. A strength of this study is the linking of TTAS callers to ED presentations within eight hours, rather than with a longer window. This short time period improves confidence in the telephone triage assessment remaining valid at the time of presentation, with likelihood of no significant change in the patient's condition. The study is limited by the inability to analyse when and by whom the triage assessment was undertaken - for example, in or out of normal business hours, or by nurse or GP. Such analysis was beyond the scope of this study and should be incorporated in future research.

\section{Conclusion}

Improving the functioning of the health system, from primary care to EDs and beyond, is challenging but a worthwhile task, in pursuit of greater effectiveness and efficiency of the system. Investigating the interactions and impact of patient inclinations with professional advice, is key to understanding, predicting and modifying consumer behaviour. TTAS can, and does, positively assist callers to access the appropriate service, at a suitable level of urgency, in a timely manner. TTAS empowers patients, particularly vulnerable members in the community, by promoting integration of care through clinical and functional service provision. There is potential for TTAS to further 
improve patient care and health system functioning. This will require greater understanding of the TTAS patient cohort, the factors that shape non-compliance and compliance with TTAS recommendations, and approaches that allow TTAS to provide medical as well as emotional support. 


\section{References}

1. McKenzie R, Dunt D, Yates A. Patient intention and self-reported compliance in relation to emergency department attendance after using an after hours GP helpline. Emerg Med Australas. 2016;28(5):538-543.

2. Bunn F, Byrne G, Kendall S. Telephone consultation and triage: effects on health care use and patient satisfaction. Cochrane Database of Systematic Reviews. 2004(3).

3. Martin C, Solaligue, M., Surate, D. Access to primary care: a complex adaptive systems lens on acuity. In: Sturmberg J, ed. The Value of Systems and Complexity Sciences for Healthcare.2016:239-246.

4. Berchet C. Emergency Care Services. OECD Publishing;2015.

5. Turner J CJ, Chambers D, et al. What evidence is there on the effectiveness of different models of delivering urgent care? A rapid review. . Southampton (UK): NIHR Journals Library.

6. Burkett E, Martin-Khan MG, Scott J, Samanta M, Gray LC. Trends and predicted trends in presentations of older people to Australian emergency departments: effects of demand growth, population aging and climate change. Australian health review : a publication of the Australian Hospital Association. 2017;41(3):246-253.

7. Lowthian JA, Curtis AJ, Cameron PA, Stoelwinder JU, Cooke MW, McNeil JJ. Systematic review of trends in emergency department attendances: an Australian perspective. Emergency medicine journal : EMJ. 2011;28(5):373-377.

8. FitzGerald G, Toloo GS, Romeo M. Emergency healthcare of the future. Emergency medicine Australasia : EMA. 2014;26(3):291-294.

9. Gibson A, Randall D, Tran DT, et al. Emergency Department Attendance after Telephone Triage: A Population-Based Data Linkage Study. Health Serv Res. 2018;53(2):1137-1162.

10. Shah S, Patel, A., Rumoro, D., Hohmann, S., Fullam, F.,. Managing patient expectations at emergency department triage,. Pat Exp J. 2015;22(2):148-157.

11. Bahadori M, Teymourzadeh E, Ravangard R, Raadabadi M. Factors affecting the overcrowding in outpatient healthcare. J Ed Health Prom. 2017;6:21-21.

12. Almomani I, AlSarheed A. Enhancing outpatient clinics management software by reducing patients' waiting time. Journal of infection and public health. 2016;9(6):734743.

13. Wang H, Ojha RP, Robinson RD, et al. Optimal measurement interval for emergency department crowding estimation tools. Annals of emergency medicine. 2017;70(5):632639.e634.

14. Wang H, Kline JA, Jackson BE, et al. The role of patient perception of crowding in the determination of real-time patient satisfaction at Emergency Department. International journal for quality in health care : journal of the International Society for Quality in Health Care. 2017;29(5):722-727.

15. Morley C, Unwin M, Peterson GM, Stankovich J, Kinsman L. Emergency department crowding: A systematic review of causes, consequences and solutions. PLOS ONE. 2018;13(8):e0203316.

16. Morris ZS, Boyle A, Beniuk K, Robinson S. Emergency department crowding: towards an agenda for evidence-based intervention. Emergency medicine journal : EMJ. 2012;29(6):460-466.

17. Nagree Y, Cameron P, Gosbell A, Mountain D. Telephone triage is not the answer to ED overcrowding. Em Med Aust. 2012;24(2):123-126. 
18. Lake R, Georgiou A, Li J, et al. The quality, safety and governance of telephone triage and advice services - an overview of evidence from systematic reviews. BMC Health Serv Res. 2017;17(1):614.

19. Adeniji AA, Mabuza LH. 'Telephone Triage': a possible means of managing the afterhours patient load at primary health care facilities in South Africa. Sth Af Fam Pract. 2018;60(6):219-224.

20. Li B, De Coster C, Quan H, Mazzei L, Elford R, Zimmer S. Follow-through after calling a nurse telephone advice line: a population-based study. Fam Prac. 2010;27(3):271278.

21. O'Connell JM, Towles W, Yin M, Malakar CL. Patient decision making: use of and adherence to telephone-based nurse triage recommendations. Medical decision making : an international journal of the Society for Medical Decision Making. 2002;22(4):309317.

22. Grol R, Giesen P, van Uden C. After-hours care in the United Kingdom, Denmark, and the Netherlands: new models. Health Aff. 2006;25(6):1733-1737.

23. Lattimer V, George S, Thompson F, et al. Safety and effectiveness of nurse telephone consultation in out of hours primary care: randomised controlled trial. The South Wiltshire Out of Hours Project (SWOOP) Group. BMJ (Clinical research ed). 1998;317(7165):1054-1059.

24. Campbell JL, Fletcher E, Britten N, et al. The clinical effectiveness and costeffectiveness of telephone triage for managing same-day consultation requests in general practice: a cluster randomised controlled trial comparing general practitionerled and nurse-led management systems with usual care (the ESTEEM trial). Health technology assessment (Winchester, England). 2015;19(13):1-212, vii-viii.

25. Meer A, Gwerder T, Duembgen L, Zumbrunnen N, Zimmermann H. Is computerassisted telephone triage safe? A prospective surveillance study in walk-in patients with non-life-threatening medical conditions. Emergency medicine journal : EMJ. 2012;29(2):124-128.

26. Lee TJ, Baraff LJ, Guzy J, Johnson D, Woo H. Does telephone triage delay significant medical treatment?: Advice nurse service vs on-call pediatricians. Archives of pediatrics \& adolescent medicine. 2003;157(7):635-641.

27. Njeru JW, Damodaran S, North F, et al. Telephone triage utilization among patients with limited English proficiency. BMC Health Serv Res. 2017;17(1):706.

28. Huibers L, Keizer E, Giesen P, Grol R, Wensing M. Nurse telephone triage: good quality associated with appropriate decisions. Fam Pract. 2012;29(5):547-552.

29. Noorani MM, Khaliq MF, Shoaib M, et al. Time intervals and associated factors of emergency treatment: first insight into Pakistani system. International archives of medicine. 2014;7(1):41.

30. Sprivulis P, Carey M, Rouse I. Compliance with advice and appropriateness of emergency presentation following contact with the HealthDirect telephone triage service. Em Med 2004;16(1):35-40.

31. Turner VF, Bentley PJ, Hodgson SA, et al. Telephone triage in Western Australia. The Medical journal of Australia. 2002;176(3):100-103.

32. Greenfield D, Nugus P, Fairbrother G, Milne J, Debono D. Applying and developing health service theory: an empirical study into clinical governance. Clin Gov 2011;16(1):8-19.

33. Pettinari CJ, Jessopp L. "Your ears become your eyes": managing the absence of visibility in NHS Direct. Journal of advanced nursing. 2001;36(5):668-675.

34. Greatbatch D, Hanlon G, Goode J, O'Cathain A, Strangleman T, Luff D. Telephone triage, expert systems and clinical expertise. Soc Health Illn. 2005;27(6):802-830. 
35. Pedersen A, Carslen, A., Bro, F., Huibers, L., Christensen, M. Quality of out-of-hours telephone triage by general practitioners and nurses: development and testing of the AQTT - an assessment tool measuring communication, patient safety and efficiency. Scand J Prim Health Care. 2019:1-12.

36. Murdoch J, Barnes R, Pooler J, Lattimer V, Fletcher E, Campbell JL. The impact of using computer decision-support software in primary care nurse-led telephone triage: Interactional dilemmas and conversational consequences. Social science \& medicine (1982). 2015;126:36-47.

37. Purc-Stephenson RJ, Thrasher C. Patient compliance with telephone triage recommendations: A meta-analytic review. Pat Ed Coun 2012;87(2):135-142.

38. Ng JY, Fatovich DM, Turner VF, Wurmel JA, Skevington SA, Phillips MR. Appropriateness of healthdirect referrals to the emergency department compared with self-referrals and GP referrals. The Medical journal of Australia. 2012;197(9):498-502.

39. McKinstry B, Hammersley V, Burton C, et al. The quality, safety and content of telephone and face-to-face consultations: a comparative study. Quality \& safety in health care. 2010;19(4):298-303.

40. Blank L, Coster J, O'Cathain A, et al. The appropriateness of, and compliance with, telephone triage decisions: a systematic review and narrative synthesis. Journal of advanced nursing. 2012;68(12):2610-2621.

41. Eastwood K, Smith K, Morgans A, Stoelwinder J. Appropriateness of cases presenting in the emergency department following ambulance service secondary telephone triage: a retrospective cohort study. BMJ Open. 2017;7(10):e016845.

42. Hamar GB, Coberley C, Pope JE, et al. Effect of post-hospital discharge telephonic intervention on hospital readmissions in a privately insured population in Australia. Australian Health Review. 2018;42(3):241-247.

43. De Coster C, Quan H, Elford R, Li B, Mazzei L, Zimmer S. Follow-through after calling a nurse telephone advice line: a population-based study. Fam Pract. 2010;27(3):271278.

44. Australian Institute of Health and Welfare. Emergency Department Care 2017-18: Australian Hospital Statistics. Canberra: AIHW;2018.

45. Gamst-Jensen H, Frishknecht E, Lippert F, et al. 67 Self-rated worry predicts hospitalisation in out-of-hours services telephone triage. BMJ Open. 2018;8(Suppl 1):A25-A26.

46. Rising KL, Carr BG, Hess EP, Meisel ZF, Ranney ML, Vogel JA. Patient-centered Outcomes Research in Emergency Care: Opportunities, Challenges, and Future Directions. Academic emergency medicine : official journal of the Society for Academic Emergency Medicine. 2016;23(4):497-502.

47. Valentijn PP, Vrijhoef HJ, Ruwaard D, Boesveld I, Arends RY, Bruijnzeels MA. Towards an international taxonomy of integrated primary care: a Delphi consensus approach. BMC family practice. 2015;16:64.

48. Tran DT, Gibson A, Randall D, et al. Compliance with telephone triage advice among adults aged 45 years and older: an Australian data linkage study. BMC Health Serv Res. 2017;17(1):512.

49. Griffin E, McCarthy JP, Thomas F, Kingham S. New Zealand Healthline call data used to measure the effect of travel time on the use of the emergency department. Social science \& medicine (1982). 2017;179:91-96. 
Table 1: Patient profile by age and disease category

\begin{tabular}{|c|c|c|}
\hline Category & Range & $\mathbf{N}(\%)$ \\
\hline Gender & Female & $1693(59)$ \\
\hline \multirow[t]{8}{*}{ Age } & $<1$ & $258(9)$ \\
\hline & $1-4$ & $375(13)$ \\
\hline & $5-9$ & $177(6)$ \\
\hline & $10-19$ & $286(10)$ \\
\hline & $20-39$ & $708(24)$ \\
\hline & $40-59$ & $563(20)$ \\
\hline & $60-79$ & $382(14)$ \\
\hline & $80>$ & $108(4)$ \\
\hline \multirow{11}{*}{$\begin{array}{l}I C D^{*}-10 \\
\text { disease } \\
\text { categories }\end{array}$} & A00-B99 Infectious and Parasitic Diseases & $246(8.6)$ \\
\hline & F00-F99 Mental and Behavioural Disorders & $82(2.9)$ \\
\hline & J00-J99 Diseases of Respiratory System & $322(11.3)$ \\
\hline & K00-K93 Diseases of Digestive System & $301(10.5)$ \\
\hline & M00-M99 Musculoskeletal system and connective tissue & $106(3.7)$ \\
\hline & N00-N99 Genitourinary & $148(5.2)$ \\
\hline & O00-0999 Pregnancy, Childbirth and puerperium & $55(1.9)$ \\
\hline & $\begin{array}{l}\text { R00-R99 Symptoms, signs, abnormal results of clinical or } \\
\text { other investigative procedure }\end{array}$ & 539 (18.9) \\
\hline & $\begin{array}{l}\text { S00-T98 Injury Poisoning and consequences of external } \\
\text { causes }\end{array}$ & $500(17.5)$ \\
\hline & $\begin{array}{l}\text { Z00-Z99 Factors influencing health status, contact with } \\
\text { health services }\end{array}$ & $210(7.3)$ \\
\hline & Others & $348(12.2)$ \\
\hline
\end{tabular}

Note: *International classification of diseases 
Table 2: Initial care inclination, care urgency assessment, recommendation and compliance

\begin{tabular}{|c|c|c|c|}
\hline $\begin{array}{c}\text { Patient initial care } \\
\text { inclination } \\
\mathrm{N}(\%)^{\dagger}\end{array}$ & $\begin{array}{c}\text { TTAS recommended high } \\
\text { urgency care } \\
\mathrm{N}(\%)^{\ddagger}\end{array}$ & $\begin{array}{c}\text { TTAS's } \\
\text { recommendation } \\
\text { for ED attendance } \\
N(\%)^{\ddagger}\end{array}$ & $\begin{array}{l}\text { Compliance with } \\
\text { TTAS's } \\
\text { recommendation } \\
\mathrm{N}(\% ; 95 \% \mathrm{Cl}) \S \text {, ๆ }\end{array}$ \\
\hline \multirow{2}{*}{$\begin{array}{c}\text { To call } \\
\text { Ambulance } 346 \\
(3)\end{array}$} & \multirow[t]{2}{*}{$346(100)$} & Via ambulance: 84 (24) & $58(69 ; 59-79)$ \\
\hline & & Via self-transport: $262(76)$ & $77(29 ; 24-35)$ \\
\hline \multirow{2}{*}{$\begin{array}{c}\text { Advice from } \\
\text { TTAS } 3534(28)\end{array}$} & \multirow[t]{2}{*}{$1040(29)$} & Via ambulance: $362(10)$ & $192(53 ; 48-58)$ \\
\hline & & Via self-transport: 678 (19) & $341(50 ; 47-54)$ \\
\hline \multirow{2}{*}{$\begin{array}{c}\text { To attend ED } \\
2851(22) \\
\end{array}$} & \multirow[t]{2}{*}{$1043(36)$} & Via ambulance: 128 (4) & $78(61 ; 52-69)$ \\
\hline & & Via self-transport: 915 (32) & $482(53 ; 49-56)$ \\
\hline \multirow{2}{*}{$\begin{array}{l}\text { To see GP } \\
2563(20)\end{array}$} & \multirow[t]{2}{*}{$474(18)$} & Via ambulance: 79 (3) & $49(62 ; 51-73)$ \\
\hline & & Via self-transport: 395 (15) & $165(42 ; 37-47)$ \\
\hline \multirow{2}{*}{$\begin{array}{l}\text { To homebased } \\
\text { care } 1525(12)\end{array}$} & \multirow[t]{2}{*}{$386(25)$} & Via ambulance: 60 (4) & $32(53 ; 41-66)$ \\
\hline & & Via self-transport: $326(21)$ & $132(40 ; 35-46)$ \\
\hline Total 10819 & & & \\
\hline
\end{tabular}

Notes: † \% calculated over 12741 TTAS callers; $¥ \%$ calculated over initial inclination; § \% calculated over TTAS's recommendation; $₫$ Compliance is assessed as per ED attendance within 8 hours

Table 3: Number of ED presentations by TTAS callers

\begin{tabular}{|c|c|c|c|}
\hline $\begin{array}{c}\text { Number of ED } \\
\text { presentations } \\
\text { per patient }\end{array}$ & $\begin{array}{c}\text { Number of } \\
\text { patients } \\
\text { accessing } \\
\text { ED }\end{array}$ & $\begin{array}{c}\text { Number of } \\
\text { patients } \\
\text { accessing ED via } \\
\text { TTAS }\end{array}$ & $\begin{array}{c}\text { TTAS patient } \\
\% \mathbf{~ ( 9 5 \% ~ C I ) ~}\end{array}$ \\
\hline 30 and over & 834 & 71 & $8.5(6.6-10.4)$ \\
\hline $20-29$ & 616 & 35 & $5.7(3.9-7.5)$ \\
\hline $10-19$ & 3483 & 117 & $3.4(2.8-4)$ \\
\hline $5-9$ & 10918 & 382 & $3.5(3.2-3.8)$ \\
\hline $2-4$ & 32662 & 1303 & $4.0(3.8-4.2)$ \\
\hline 1 only & 24064 & 949 & $3.9(3.7-4.2)$ \\
\hline Total & 72577 & 2857 & \\
\hline
\end{tabular}

Table 4: TTAS callers ED triage outcomes

\begin{tabular}{|l|c|c|c|}
\hline \multicolumn{1}{|c|}{ Triage categories } & $\begin{array}{c}\text { Number of } \\
\text { patients } \\
\text { accessing ED }\end{array}$ & $\begin{array}{c}\text { Number of } \\
\text { patients } \\
\text { accessing ED via } \\
\text { TTAS }\end{array}$ & $\begin{array}{c}\text { TTAS } \\
\text { patient } \\
\%(\mathbf{9 5 \%} \text { CI) }\end{array}$ \\
\hline Category 1: immediate medical attention & 423 & 4 & $0.9(0.0-1.9)$ \\
\hline $\begin{array}{l}\text { Category 2: medical attention within 10 } \\
\text { minutes }\end{array}$ & 6810 & 168 & $2.5(2.1-2.8)$ \\
\hline $\begin{array}{l}\text { Category 3: medical attention within 30 } \\
\text { minutes }\end{array}$ & 25978 & 1208 & $4.7(4.6-4.9)$ \\
\hline Category 4: medical attention within 1 hour & 32676 & 1358 & $4.2(3.9-4.4)$ \\
\hline $\begin{array}{l}\text { Category 5: medical attention within 2 } \\
\text { hours }\end{array}$ & 6421 & 117 & $1.8(1.5-2.1)$ \\
\hline Total & $72308^{\dagger}$ & $2855^{\ddagger}$ & 4 \\
\hline
\end{tabular}

Note: ${ }^{\dagger}$ Triage information of the 269 of 72557 ED presentations were not accessible in the record. ${ }^{\ddagger}$ Triage information of the 2 of 2857 ED presentations were not accessible in the record. 
Table 5: ED appropriate presentations for non-TTAS and TTAS callers

\begin{tabular}{|c|c|c|}
\hline ED appropriate care & $\begin{array}{c}\text { Non-TTAS callers }(\% ; 95 \% \text { CI) } \\
+\end{array}$ & $\begin{array}{c}\text { TTAS callers }(\% ; 95 \% \text { CI) } \\
\ddagger\end{array}$ \\
\hline Triage 1,2 or 3 & $31831(46 ; 45.1-46.2)$ & $1380(48 ; 45.7-50.9)$ \\
\hline Admitted to Hospital & $4502(6 ; 5.7-7.2)$ & $150(5 ; 1.7-8.8)$ \\
\hline Recent Admission & $3482(5 ; 4.3-5.7)$ & $199(7 ; 3.4-10.5)$ \\
\hline Total ED appropriate & $39815(57 ; 56.6-57.6)$ & $1729(61 ; 58-63)$ \\
\hline Total presentations & 69729 & 2857 \\
\hline
\end{tabular}

Note: $\%$ calculated over 69729 non-callers who accessed ED. $¥ \%$ calculated over 2857 TTAS callers who accessed ED. 